\title{
Papers
}

\section{Training care givers of stroke patients: economic evaluation}

\author{
Anita Patel, Martin Knapp, Andrew Evans, Inigo Perez, Lalit Kalra
}

\begin{abstract}
Background Training care givers reduces their burden and improves psychosocial outcomes in care givers and patients at one year. However, the cost effectiveness of this approach has not been investigated.

Objective To evaluate the cost effectiveness of caregiver training by examining health and social care costs, informal care costs, and quality adjusted life years in care givers.

Design A single, blind, randomised controlled trial. Setting Stroke rehabilitation unit.

Subjects 300 stroke patients and their care givers.

Interventions Caregiver training in basic nursing and facilitation of personal care techniques compared with no care giver training.
\end{abstract}

Main outcome measures Health and social care costs, informal care costs, and quality adjusted life years in care givers over one year after stroke.

Results Total health and social care costs over one year for patients whose care givers received training were significantly lower (mean difference - $£ 4043$ (\$7249; €6072), 95\% confidence interval $-£ 6544$ to $-£ 1595$ ). Inclusion of informal care costs, which were similar between the two groups, did not alter this conclusion. The cost difference was largely due to differences in length of hospital stay. The EQ-5D did not detect changes in quality adjusted life years in care givers.

Conclusion Compared with no training, caregiver training during rehabilitation of patients reduced costs of care while improving overall quality of life in care givers at one year.

\section{Introduction}

Informal care givers make an important contribution to supporting disabled stroke survivors at home, often at a great personal cost. ${ }^{1-5}$ The United Kingdom health and community care reforms of the 1990s seem to have done little to provide support for care givers ${ }^{6}$ but may have increased the burden of care. ${ }^{7}$ Studies on caregiver interventions show limited benefits; their cost effectiveness has not been evaluated. ${ }^{8}$ This study reports an economic evaluation of an intervention that entailed training care givers, carried out within a randomised controlled trial. $^{9}$

\section{Methods}

Full details of the study design, subjects, ethical approval, randomisation, intervention, outcome assessment, and data analysis have been given previously. ${ }^{9}$ To summarise, 300 patients and their care givers were randomised to receive caregiver training and not to receive training, in addition to conventional care on a stroke rehabilitation unit. This training consisted of instruc- tion in basic skills of moving and handling, facilitation of activities of daily living, and simple nursing tasks; care givers received training over three to five sessions, lasting for 30-45 minutes each, and a follow up session at home.

\section{Assessment of care givers' quality of life}

We used the EuroQol five-dimensional questionnaire (EQ-5D) $)^{10}$ at baseline, and at 4, 12, 26, and 52 weeks after stroke to carry out assessments. We imputed missing values for eight care givers with partially missing EQ-5D data by carrying forward the last value. We did not impute missing data if caregiver data were missing at all assessment points, if no caregiver data were available from week 4 assessment onwards (to avoid an upwards bias due to carrying forward baseline pre-stroke values), and if a patient died before the care giver's missing assessment. We applied utility weights from a UK general population survey ${ }^{11}$ to EQ-5D health states to calculate quality adjusted life years (QALYs). We assumed measures of health state at each assessment point to represent the time since the last assessment. We therefore multiplied QALYs for each assessment point by the relevant proportion of a year and summed these proportional tariffs to represent a complete year after onset of stroke. We examined QUALY outcomes in terms of change between baseline and week 52. As we anticipated decreases in quality of life between baseline and follow up, we made comparisons between groups based on minimising losses in QUALYs.

\section{Use of resources}

We adopted a societal perspective, including health services, other formal care agencies, and informal carers for the economic evaluation. We collected data on use of health and social care services over one year after onset of stroke and on use of hospital resources for a three month period before stroke. Therapists providing treatment recorded data on hospital use and therapy input after stroke. We used a specially adapted version of the client service receipt inventory to collect data on use of services after discharge from hospital retrospectively, at 12, 26, and 52 weeks during patients' assessment interviews. ${ }^{12}$ We verified the completeness and accuracy of data on use of resources of hospital and social services against records of service providers. "Initial admission" includes the admission to the stroke unit and therapy inputs received while on the unit. "12 month follow up" covers any subsequent hospital use, social services, and input of informal care during the 12 month follow up period.

\section{Costs}

To obtain a cost per patient we multiplied resource volumes by unit costs. Local services provided unit costs, to approximate 
actual intervention costs. Some local unit costs were based on charges rather than costs. We used national statistics when local costs were not available. ${ }^{13}$ We used the opportunity cost method (the value of the opportunities forgone by care givers as a result of time spent on care giving) to estimate the cost of informal care. We used the United Kingdom minimum wage ( $£ 4.10$ per hour $^{14}$ ) as a proxy valuation of their time. We used the NHS Executive's hospital and community health services inflation index or personal social services inflation index, ${ }^{13}$ as relevant, to standardise all costs to 2001-2 prices. Table 1 shows unit costs.

\section{Data analysis and statistical methods}

The primary outcome measure for the study was health and social care costs during the first year after onset of stroke. We analysed the data on an intention to treat basis. Data were incomplete for those patients who died before the end of the study and their care givers, and for some survivors and their care givers. We included all available data in the analyses. All costs are reported as mean values with standard deviations. We used Student's $t$ test to compare differences between groups and non-parametric bootstrap methods, with 5000 repetitions, to obtain $95 \%$ confidence intervals.

\section{Results}

We found no significant difference between the training and the no training groups for the number of patients who died, or the number of days that they were alive $(\mathrm{P}=0.88)$. It was therefore not necessary to adjust cost data for differential survival time.

\section{Quality adjusted life years}

Mean QALY values for trained and untrained care givers were comparable at baseline (0.94 (SD 0.10) $v 0.94$ (SD 0.14)) and at one year (0.91 (SD 0.11) v 0.90 (SD 0.14)). We found no significant difference between groups in QALY losses between baseline and one year. Given that the visual analogue scale detected changes over time and a difference between the groups (accompanying paper), it is likely that the EQ-5D was insensitive to change in care givers' health related quality of life, rather than that there were no effects on QALYs.

\section{Resource use and costs}

The two groups used resources to a similar extent at baseline (table 2). Patients in the training group stayed in hospital less long (mean difference -12.4 days, 95\% confidence interval -19.5 to -5.6$)$ and had less physiotherapy ( -30.2 units, -51.8 to -8.9$)$ and occupational therapy $(-3.2$ units, -4.8 to -1.6$)$ than patients in the no training group. Use of speech and language therapy was similar between the two groups. The differences in use of therapy are likely to be due to the longer stay in hospital in the no training group. About a third of patients in both groups received help from social services with personal care, and 14-17\% received domestic help. Although a trend towards lesser use of personal and domestic care services

Table 1 Summary of unit costs and sources of information

\begin{tabular}{|c|c|c|}
\hline Item & Unit cost in $£$, at 2001-2 prices & Source \\
\hline \multicolumn{3}{|l|}{ Initial admission for stroke } \\
\hline Stroke unit per day & 233.34 & Business Centre, Finance and Contracting, Bromley Hospitals NHS Trust, 1998 \\
\hline Physiotherapist per personal interaction unit & 9.68 & Business Centre, Finance and Contracting, Bromley Hospitals NHS Trust, 1998 \\
\hline Occupational therapist per personal interaction unit & 9.68 & Business Centre, Finance and Contracting, Bromley Hospitals NHS Trust, 1998 \\
\hline Hospital speech and language therapist per minute of patient contact & 0.70 & Netten and Curtis, $2002^{13}$ \\
\hline \multicolumn{3}{|l|}{ Other secondary care services } \\
\hline General medical ward per day & 297.63 & Business Centre, Finance and Contracting, Bromley Hospitals NHS Trust, 1998 \\
\hline Outpatient visit & 82.00 & Netten and Curtis, $2002^{13}$ \\
\hline Accident and emergency per visit & 75.00 & Netten and Curtis, $2002^{13}$ \\
\hline Day hospital per visit & 57.00 & Netten and Curtis, $2002^{13}$ \\
\hline \multicolumn{3}{|l|}{ Social services } \\
\hline Personal care per hour & 13.72 & Bromley Social Services, unpublished data, 1997 \\
\hline Domestic assistance per 1 hour contact & 12.85 & Bromley Social Services, unpublished data, 1997 \\
\hline Laundry assistance per 1 hour contact & 12.85 & $\begin{array}{l}\text { In the absence of a specific unit cost for this service, domestic assistance unit } \\
\text { cost used as a proxy }\end{array}$ \\
\hline Shopping assistance per 1 hour contact & 12.85 & $\begin{array}{l}\text { In the absence of a specific unit cost for this service, domestic assistance unit } \\
\text { cost used as a proxy }\end{array}$ \\
\hline Meals on wheels per meal & 2.35 & Bromley Social Services, unpublished data, 1997 \\
\hline Carelink per 15 minute contact & 3.43 & $\begin{array}{l}\text { In the absence of a specific unit cost for this service, an estimate was based on } \\
\text { the following assumptions: the service is usually provided by a social services } \\
\text { personal care professional, contacts are usually made over the telephone, and } \\
\text { that such contacts are approximately } 15 \text { minutes in duration. Therefore, unit } \\
\text { cost is } 25 \% \text { of a personal care contact }\end{array}$ \\
\hline Social services day care centre per session & 33.09 & Netten and Curtis, $2002^{13}$ \\
\hline \multicolumn{3}{|l|}{ Community based care } \\
\hline General practitioner per surgery visit & 16.00 & Netten and Curtis, $2002^{13}$ \\
\hline General practitioner per home visit & 49.00 & Netten and Curtis, $2002^{13}$ \\
\hline District nurse per minute of home visit & $0.89+1.13$ travel & Netten and Curtis, $2002^{13}$ \\
\hline Dentist per 20 minute visit & 19.05 & Health and Personal Social Services Statistics, 1996 \\
\hline Optician per visit & 15.91 & $\begin{array}{l}\text { Doctors and Dentists Remuneration. Twenty-fifth report. London: Stationery } \\
\text { Office, } 1996\end{array}$ \\
\hline Chiropody per clinic visit & 10.19 & Netten and Curtis, $2002^{13}$ \\
\hline Chiropody per home visit & $19.30+1.13$ travel & Netten and Curtis, $2002^{13}$ \\
\hline Respite care per week & 537.74 & Netten and Curtis, $2002^{13}$ \\
\hline \multicolumn{3}{|l|}{ Informal care } \\
\hline Domestic assistance per 1 hour contact & 12.85 & Bromley Social Services, unpublished data, 1997 \\
\hline United Kingdom national minimum wage per hour & 4.10 & $\begin{array}{l}\text { Department of Trade and Industry. A detailed guide to the national minimum } \\
\text { wage, October 2001. www.dti.gov.uk/er/nmw/gtmw.pdf (accessed } 19 \text { Sep 2003). }{ }^{14}\end{array}$ \\
\hline
\end{tabular}


Table 2 Use of resources in the first year after onset of stroke

\begin{tabular}{|c|c|c|c|c|c|c|}
\hline & \multicolumn{3}{|c|}{ Training } & \multicolumn{3}{|c|}{ No training } \\
\hline & No of patients & $\begin{array}{l}\text { No (\%) of patients using } \\
\text { service or resource }\end{array}$ & Mean* & No of patients & $\begin{array}{l}\text { No (\%) of patients using } \\
\text { service or resource }\end{array}$ & $\operatorname{Mean}^{\star}$ \\
\hline \multicolumn{7}{|l|}{ Initial admission for stroke } \\
\hline Stroke unit in days & 151 & $151(100.0)$ & 30.8 & 149 & $149(100.0)$ & 43.2 \\
\hline Physiotherapy in personal interaction units $†$ & 151 & $151(100.0)$ & 115.1 & 149 & $149(100.0)$ & 145.3 \\
\hline Occupational therapy in personal interaction units $\dagger$ & 151 & $150(99.3)$ & 9.3 & 149 & $149(100.0)$ & 12.4 \\
\hline Speech and language therapy in hours & 151 & $87(57.6)$ & 6.7 & 149 & $82(55.0)$ & 5.3 \\
\hline \multicolumn{7}{|l|}{12 months afterwards } \\
\hline \multicolumn{7}{|l|}{ Secondary care: } \\
\hline Admissions in days & 134 & $11(8.2)$ & 10.9 & 126 & $10(7.9)$ & 12.8 \\
\hline Outpatients in visits & 134 & $57(42.5)$ & 2.2 & 126 & $53(42.1)$ & 2.3 \\
\hline No of visits to accident and emergency & 134 & $1(0.7)$ & 3.0 & 126 & $3(2.4)$ & 1.0 \\
\hline Day hospital in visits & 134 & $38(28.4)$ & 5.6 & 126 & $24(19.0)$ & 7.2 \\
\hline \multicolumn{7}{|l|}{ Social services: } \\
\hline Personal care in contacts & 151 & $56(37.1)$ & 247.4 & 149 & $50(33.6)$ & 317.7 \\
\hline Domestic assistance in contacts & 151 & $22(14.6)$ & 29.2 & 149 & $26(17.4)$ & 32.0 \\
\hline Carelink in contacts & 151 & $10(6.6)$ & 248.5 & 149 & $15(10.1)$ & 246.8 \\
\hline Laundry assistance in contacts & 151 & $6(4.0)$ & 30.8 & 149 & $9(6.0)$ & 42.3 \\
\hline Shopping assistance in contacts & 151 & $19(12.6)$ & 26.8 & 149 & $17(11.4)$ & 32.0 \\
\hline Meals on wheels in meals & 151 & $16(10.6)$ & 202.5 & 149 & $24(16.1)$ & 170.0 \\
\hline Day care in visits & 151 & $14(9.3)$ & 18.6 & 149 & $26(17.4)$ & 25.8 \\
\hline \multicolumn{7}{|l|}{ Other community based care (visits): } \\
\hline General practitioner in surgery & 134 & $84(62.7)$ & 2.9 & 125 & $68(54.4)$ & 3.2 \\
\hline General practitioner at patient's home & 134 & $47(35.1)$ & 3.0 & 125 & $54(43.2)$ & 2.7 \\
\hline District nurse at patient's home & 134 & $41(30.6)$ & 7.4 & 127 & $31(24.4)$ & 6.4 \\
\hline Dentist & 134 & $30(22.4)$ & 1.6 & 125 & $31(24.8)$ & 1.5 \\
\hline Optician & 134 & $35(26.1)$ & 1.1 & 125 & $35(28.0)$ & 1.3 \\
\hline Chiropody in clinic & 134 & $21(15.7)$ & 1.3 & 125 & $16(12.8)$ & 1.6 \\
\hline Chiropody at home & 134 & $7(5.2)$ & 1.7 & 125 & $8(6.4)$ & 1.9 \\
\hline Respite care in weeks & 151 & $7(4.6)$ & 3.7 & 149 & $12(8.1)$ & 3.0 \\
\hline
\end{tabular}

* Mean for users only.

† One personal interaction unit is equivalent to approximately 30 minutes.

became obvious in the training group, the difference was significant only for use of day care ( -2.8 visits, -5.1 to -0.5$)$.

Sixty per cent of total annual costs in each group were accounted for by bed days during the initial admission, which rose to $80 \%$ after including therapy costs (table 3 ). These costs were significantly lower in the training group $(\mathrm{P}<0.0001)$ and were due to the shorter initial stay in hospital rather than reduced costs in the 12 months after stroke.

The number of care givers providing assistance to patients in various informal care activities increased in both groups compared with baseline (table 4 and table 5). We found no significant differences in the average number of care hours provided per day, the number of days that such care was provided, or the total average annual number of care hours. Informal care, costed at minimum wage, amounted to an average of $£ 884$ (\$1585; €1328) (SD £1482) in the training and £933 (SD £1283) in the no training group. The addition of these to total annual costs did not alter the finding that the training group had lower total costs.

Table 3 Mean costs in $£$, at 2001-2 prices, in the first year after onset of stroke

\begin{tabular}{|c|c|c|c|c|c|c|}
\hline & \multicolumn{2}{|c|}{ Training $(n=151)$} & \multicolumn{2}{|c|}{ No training ( $n=149$ ) } & \multicolumn{2}{|c|}{ Training $v$ no training } \\
\hline & $\begin{array}{l}\text { No of patients } \\
\text { using service or } \\
\text { resource }\end{array}$ & Mean (SD) & $\begin{array}{l}\text { No of patients } \\
\text { using service or } \\
\text { resource }\end{array}$ & Mean (SD) & Mean difference (BS, 95\% Cl) & $P$ value \\
\hline \multicolumn{7}{|l|}{ Initial admission for stroke } \\
\hline Stroke unit & 151 & 7189 (6177) & 149 & 10079 (7 851) & $-2890(-4515$ to -1301$)$ & $<0.001$ \\
\hline Therapy & 151 & $1365(1087)$ & 149 & $1650(1043)$ & $-285(-525$ to -37$)$ & 0.021 \\
\hline Total & 151 & 8554 (6939) & 149 & $11729(8506)$ & $-3176(-4980$ to -1409$)$ & $<0.001$ \\
\hline \multicolumn{7}{|l|}{12 month follow up period } \\
\hline Secondary care & 134 & $434(1399)$ & 125 & $555(2317)$ & $-120(-633$ to 303$)$ & 0.611 \\
\hline Social services & 151 & 1235 (2708) & 149 & 1471 (2 898) & -236 (-881 to 402) & 0.466 \\
\hline Other community based care & 134 & $221(501)$ & 125 & $258(491)$ & $-38(-159$ to 86$)$ & 0.544 \\
\hline Informal care & 134 & $884(1482)$ & 125 & 933 (1 283) & -49 (-392 to 303$)$ & 0.777 \\
\hline Total excluding informal care & 134 & $1953(3400)$ & 125 & $2494(4060)$ & -541 (-1479 to 353$)$ & 0.244 \\
\hline Total including informal care & 134 & 2837 (4182) & 125 & 3427 (4 409) & $-590(-1634$ to 469$)$ & 0.270 \\
\hline \multicolumn{7}{|l|}{ Total annual costs } \\
\hline Total excluding informal care & 134 & 10544 (9278) & 125 & $14587(10844)$ & $-4043(-6544$ to -1595$)$ & 0.001 \\
\hline Total including informal care & 134 & $11429(9825)$ & 125 & $15520(11106)$ & $-4091(-6675$ to -1578$)$ & 0.002 \\
\hline
\end{tabular}

$\mathrm{SD}=$ standard deviation, $\mathrm{BS}=$ bootstrap, $\mathrm{Cl}=$ confidence interval 
Table 4 Informal care inputs. Values are numbers (percentages) of patients using a service or resource

\begin{tabular}{|c|c|c|c|c|}
\hline \multirow[b]{2}{*}{ Service or resource } & \multicolumn{2}{|c|}{ Training } & \multicolumn{2}{|c|}{ No training } \\
\hline & Baseline ( $n=134)$ & After stroke ( $n=133)$ & Baseline ( $n=124)$ & After stroke ( $n=124)$ \\
\hline Personal care & $8(6.0)$ & $50(37.6)$ & $6(4.8)$ & $43(34.7)$ \\
\hline Mobility & $5(3.7)$ & $42(31.6)$ & $7(5.6)$ & $29(23.4)$ \\
\hline Meal preparation & $10(7.5)$ & $49(36.8)$ & $12(9.7)$ & $38(30.6)$ \\
\hline Housework & $11(8.2)$ & $52(39.1)$ & $18(14.5)$ & $46(37.1)$ \\
\hline Shopping & $16(11.9)$ & $59(44.4)$ & 24 (19.3) & $59(47.6)$ \\
\hline Outings & $17(12.7)$ & 64 (48.1) & $22(17.9)$ & $59(47.6)$ \\
\hline
\end{tabular}

\section{Sensitivity analyses}

We carried out sensitivity analyses on two aspects of the evaluation to assess the robustness of the findings. As methods of costing informal care inputs remain controversial, ${ }^{15}$ we used the replacement cost method (the cost of replacing inputs of informal care givers with professional care) to estimate the costs of informal care. Applying the cost of a home care worker from social services $\left(£ 12.85\right.$ per hour $\left.{ }^{13}\right)$ increased the average cost of informal care in each group but did not affect comparisons of total costs (table 6). Further, as differences in cost were attributable mainly to differences in the duration of initial hospitalisation between the two groups, we examined the effect of increasing the length of stay of patients in the training group by $10 \%, 15 \%$, and 20\%. Differences between the groups in hospitalisation costs remained, with an up to $15 \%$ increase in the training group's length of stay and in total annual costs for health and social care with up an to $20 \%$ increase in length of stay.

\section{Cost effectiveness}

It was not necessary to calculate incremental cost effectiveness ratios because the caregiver training was clearly the more desirable option, with both lower costs and better outcomes.

\section{Discussion}

Improving the skills of consenting informal care givers during the rehabilitation of inpatients reduces costs for stroke care and improves their quality of life without increasing the burden of care to families or transferring costs to the community. Previous evaluations of caregiver interventions lack reliable cost effectiveness analyses because of difficulties in deciding the domains and timeframes for such assessments. ${ }^{16}$

Training care givers did not substantially reduce use or costs of resources in the community after discharge from hospital. This may be because many stroke patients receive only little statutory support where further reductions were not possible or because decreased needs in some areas may have been balanced by increased needs in areas not identified previously. The possibility exists that the trends towards lower personal and domestic care costs may have reached significance in a larger sample.

\section{Potential biases}

Cost advantages seem to be a result of earlier discharge from hospital in the training group. This unexpected finding has several potential explanations. The most likely reason is that training and some input into care before discharge may have increased the confidence and competence of care givers, who were more capable of continuing rehabilitation practices at home. Interestingly, more patients in this group had achieved independence in their abilities for personal care at three months than in the no training group. ${ }^{9}$ It is also possible that patients' and care givers' awareness that they were receiving extra interventions or these families being viewed as "special" by the multidisciplinary team may have expedited discharge, although there was no evidence to show that they received more therapy input, more benefits, or more community support after discharge. Finally, complete blinding to intervention is not possible in pragmatic therapy based trials, especially when care givers are involved in discharge planning process. The possibility of bias due to unblinding was considered to be small because length of hospital stay was not a predefined outcome measure, the team deciding discharge was different to the research team, and sensitivity analyses showed that findings remained valid even when the length of stay was increased by $20 \%$ in these patients.

\section{Weaknesses of the study}

Our assessment of costs did not include the initial investment into developing the training intervention. The ongoing costs of training care givers were also embedded within the activity returned by the therapists and difficult to dissect from overall costs of therapy. A cost of between $£ 150$ (three 30 minute sessions and one home visit) and $£ 285$ (five 45 minute sessions and one home visit) per trained care giver is suggested by the protocol, but this is likely to be an underestimation that does not reflect true service costs. The inclusion of these costs would equalise costs of therapy but not affect comparisons between groups.

The EQ-5D seemed insensitive to changes in care givers' QALYs. Although the EQ-5D has previously been used successfully with care givers, ${ }^{17}$ others have shown it to be less sensitive in

Table 5 Informal care inputs received over and above baseline levels

\begin{tabular}{|c|c|c|c|c|c|c|c|c|}
\hline \multirow[b]{3}{*}{$\begin{array}{l}\text { Informal care received over } \\
\text { and above baseline values }\end{array}$} & \multicolumn{4}{|c|}{ Full sample } & \multicolumn{4}{|c|}{ Among those actually receiving informal care } \\
\hline & \multicolumn{2}{|c|}{ Training $(n=134)$} & \multicolumn{2}{|c|}{ No training $(n=125)$} & \multicolumn{2}{|c|}{ Training $(\mathrm{n}=86)$} & \multicolumn{2}{|c|}{ No training $(\mathrm{n}=73)$} \\
\hline & $\begin{array}{l}\text { No of patients } \\
\text { using service or } \\
\text { resource }\end{array}$ & Mean (SD) & $\begin{array}{l}\text { No of patients } \\
\text { using service or } \\
\text { resource }\end{array}$ & Mean (SD) & $\begin{array}{l}\text { No of patients } \\
\text { using service or } \\
\text { resource }\end{array}$ & Mean (SD) & $\begin{array}{l}\text { No of patients } \\
\text { using service or } \\
\text { resource }\end{array}$ & Mean (SD) \\
\hline Mean hours per day & 134 & $0.8(1.2)$ & 125 & $0.8(1.0)$ & 86 & $1.3(1.3)$ & 72 & $1.4(1.0)$ \\
\hline $\begin{array}{l}\text { Mean number of days care } \\
\text { was received over the } \\
12 \text { month follow up period }\end{array}$ & 134 & $175.1(160.3)$ & 125 & $156.4(156.0)$ & 86 & $272.8(115.1)$ & 72 & $271.5(104.0)$ \\
\hline $\begin{array}{l}\text { Mean total hours over the } \\
12 \text { month follow up period }\end{array}$ & 134 & $215.7(361.4)$ & 125 & $227.6(313.0)$ & 86 & $336.0(404.3)$ & 72 & $395.1(322.5)$ \\
\hline
\end{tabular}


Table 6 Sensitivity analyses: effects of increased length of stroke admission in the training group and alternative method of informal care costing

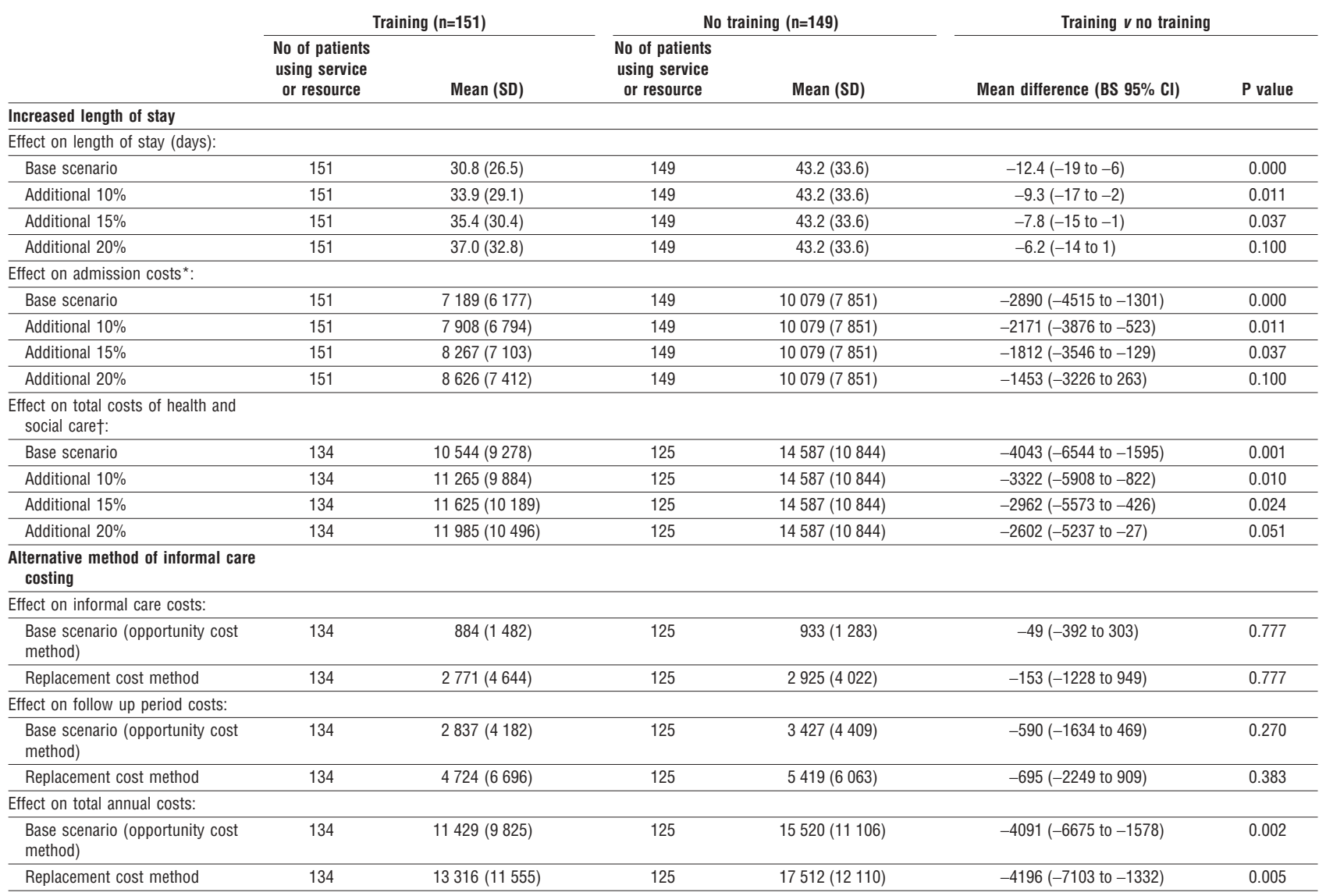

$\mathrm{SD}=$ standard deviation, $\mathrm{BS}=$ bootstrap, $\mathrm{Cl}=$ confidence interval

*Excluding therapy costs.

†Excluding informal care costs.

detecting small changes towards the top end of the scale ${ }^{18}$ and less sensitive than programme specific instruments. ${ }^{19}$

\section{Strength of the study}

We examined costs as well as changes in health outcomes. In addition, the study takes into consideration the possibility of shifting costs from statutory services to informal care and shows that caregiver training can reduce costs of formal care without shifting costs on to care givers, while improving clinical outcomes in care givers and patients. ${ }^{9}$

\section{Conclusion}

Despite care givers being recognised as one of the building blocks of community care,$^{20}$ and English national strategy ("Caring about Carers") prioritising information, support, and care for care givers, ${ }^{21}$ little is known about how care givers can be assisted effectively. Improving the skills of consenting informal care givers during inpatient rehabilitation reduces stroke care costs and improves their quality of life without increasing the burden of care to families or transferring costs to the community.

We acknowledge the contributions made by all hospital, general practice, community health, and social services staff to the project. Particular thanks are owed to Shirley Law and Caroline Oates of the Carer Information and Support Services in Bromley and to Jayne Steadman, Judith Eade, and Magreet Whittink, who participated in the care giver training programme. Contributors: AP was responsible for the analysis and interpretation of the data and drafting of the paper. MK was involved in the conception and design of the study, interpretation of data and writing of the paper. LK was responsible for the conception, design, initiation, and overall coordination

\section{What is already known on this topic}

In England care givers are increasingly being recognised as one of the building blocks of community care

Little is known, however, about the costs of assisting care givers effectively

\section{What this study adds}

Training care givers reduces health and social care costs in the first year after stroke compared with not training them

Costs of informal care are similar between trained and untrained care givers, and therefore no shift in the burden of care from statutory services towards carers is becoming apparent

Caregiver training is associated with smaller losses of quality of life among care givers; this effect is apparent soon after the patient's stroke

The EQ-5D questionnaire did not detect changes in care givers' quality adjusted life years

of the study, interpretation of data and drafting of the paper. $\mathrm{AE}$ was responsible for collation of data and critical review of the paper. IP was involved in the design of the study, day to day administration of the study, 
data collection, and data entry. LK will act as the guarantor of the paper on behalf of all investigators.

Funding: The project was funded by the NHS R\&D Executive's Primary Secondary Interface Priority Programme (Project No: F-4/1997).

Competing interests: None declared.

Ethical approval: Bromley Research Ethics Committee (LREC/106).

1 Wilkinson PR, Wolfe CDA, Warburton FG, Rudd AG, Howard RS, Ross-Russell RW, et al. A long-term follow-up of stroke patients. Stroke 1997;28:507-12

2 Claesson L, Gosman-Hedstrom G, Johannesson M, Fagerberg B, Blomstrand C Resource utilization and costs of stroke unit care integrated in a care continuum: a 1-year controlled, prospective, randomized study in elderly patients: the Goteborg $70+$ stroke study. Stroke 2000;31:2569-77.

3 Dewey HM, Thrift AG, Mihalopoulos C, Carter R, Macdonell RA, McNeil JJ, Donnan GA. Informal care for stroke survivors: results from the north east Melbourne stroke incidence study (NEMESIS). Stroke 2002;33:1028-33.

4 Anderson CS, Linto J, Stewart-Wynne EG. A population-based assessment of the impact of caregiving for long-term stroke survivors. Stroke 1995;26:843-9.

5 Bugge C, Alexander H, Hagen S. Stroke patients' informal caregivers. Patient, caregiver, and service factors that affect caregiver strain. Stroke 1999:30:1517-23.

6 Parker G, Clarke H. Making ends meet: do carers and disabled people have a common agenda? Policy Politics 2002;30:347-59.

7 Bauld L, Chesterman J, Davies B, Judge K, Mangalore R. Caring for older people: an assessment of community care in the 1990s. Aldershot: Ashgate, 2000.

8 Forster A, Smith J, Young J, Knapp P, House A, Wright J. Information provision for stroke patients and their caregivers. Cochrane Database Syst Rev 2001;(3):CD001919.

9 Kalra L, Evans A, Perez I, Melbourn A, Patel A, Knapp M, et al. Training care givers of stroke patients: randomised controlled trial. BMJ 2004;328:1099-101.

10 The EuroQol Group. EuroQol: a new facility for the measurement of health related quality of life. Health Policy 1990;16:199-208.

11 Dolan P, Gudex C, Kind P, Williams A. A social tariff for EuroQol:results from a UK population survey. Discussion paper 138. York: University of York, 1995

12 Beecham J, Knapp M. Costing psychiatric interventions. In: Thornicroft G, Brewin C, Wing J, eds. Measuring mental health needs. London: Gaskell, 1992.
13 Netten A Curtis L. Unit costs of health and social care. Canterbury: Personal and Social Services Research Unit, University of Kent, Canterbury, 2002

14 Department of Trade and Industry. A detailed guide to the national minimum wage, October 001. www.dti.gov.uk/er/nmw/gtmw.pdf (accessed 19 Sep 2003).

15 McDaid D. Estimating the costs of informal care for people with Alzheimer's disease methodological and practical challenges. Int J Geriatr Psychiatry 2001;16:400-5.

16 Godber E, Robinson R, Steiner E. Economic evaluation and the shifting balance towards primary care: definitions, methods and methodological issues. Health Ecom 1997;6:275-94.

17 Gunnell D, Coast J, Richards SH, Peters TJ, Pounsford JC, Darlow M-A. How great burden does early discharge to hospital-at-home impose on carers? A randomized controlled trial. Age Ageing 2000;29:137-42.

18 Longworth L, Bryan S. An empirical comparison of EQ-5D and SF-36 in liver transplant patients. Health Econ (in press)

19 Donaldson C, Atkinson A, Bond J. Should QALYs be programme-specific? J Health Econ 1988;7:239-57.

20 Twigg J. Informal care of older people. In: Bernard M, Phillips L, eds. The social policy of old age. London: Centre for Policy on Ageing, 1998:128-41.

21 Department of Health. Caring about carers: a national strategy for carers. London: $\mathrm{DoH}$ 1999.

(Accepted 5 March 2004)

bmj.com 2004;328:1102

Centre for the Economics of Mental Health, Institute of Psychiatry, London SE5 8AF

Martin Knapp professor of health economics

Anita Patel lecturer in health economics

Department of Medicine, Guy's, King's and St Thomas's School of Medicine, London SE5 9PJ

Lalit Kalra professor of stroke medicine

Andrew Evans clinical lecturer in stroke medicine

Inigo Perez research fellow

Correspondence to: L Kalra lalit.kalra@kcl.ac.uk 